\title{
The Moderating Effect of Personal Cultural Orientation on Brand Association and Conspicuous Consumptions: A Study in the Context of Luxury Fashion Brand Market in Sri Lanka
}

\author{
A.A.D.C. Perera ${ }^{* 1}$, S.M.A.K. Samarakoon ${ }^{2}$ and W.M.C.B. Wanninayake ${ }^{3}$ \\ ${ }^{13}$ Department of Marketing Management, University of Kelaniya, Sri Lanka \\ ${ }^{2}$ Department of Commerce and Financial Management, University of Kelaniya, Sri Lanka \\ * Corresponding Author; dileshaperera@gmail.com
}

\begin{abstract}
Sri Lanka being a country where the luxury brand market is at an elementary stage, it is vital for luxury marketers to better understand the luxury consumer-brand relationship, have an in depth understanding about the market and customer dynamics, to strategize the conspicuous brand appeals in their branding and promotional strategies. The overall purpose of reaching such an understanding is to develop a strong brand architecture. Moreover, how the Sri Lankan culture would react to their marketing communication concepts does hold some ambiguity given the fact that culture plays a major role in influencing consumer behavior and purchase intention. It was noted that there is no common agreement among previous researchers regarding the subject matter. Further it is not appropriate to apply concepts in other parts of the world in Sri Lankan context given the fact that we have a diverse cultural background. In addition, this research area is a new endeavor in the Sri Lankan context as it was noted that there is a scarcity of literature of the theme of the present study in published sources. The target population of the study is the global middle-class population who spend (PPP) more than $10 \$$ and less than $100 \$$ a day per capita and the rich (upper) class population who spends more than $100 \$$ a day per capita. The sample size of the study was 634 respondents. Both the online survey and field interviews were simultaneously carried out as data collection methods. Both descriptive and inferential statistics were used to presenting and analyzing the data. Further the main data analytical tool which was used for the present study was PLS-SEM 3. The SPSS 23 software also used for the other analysis needed for the study. Based on the findings it was revealed that there is a significance relationship between brand association and conspicuous consumption. Further it was discovered that there is a mediating impact from self-concept to the relationship between brand association and conspicuous consumption. Accordingly, this research offers useful guidance to decision makers of the existing brands in the current market as well as the new brands in the context of the luxury brands market in Sri Lanka in planning their marketing strategies, to shape their marketing communication, segmenting their markets based on the findings given in the study.
\end{abstract}

Keywords: Brand Association, Conspicuous Consumption, Luxury Fashion Brand Market, Personal Cultural Orientation.

\section{INTRODUCTION}

Consumer behavior dynamics vary from country to country and culture to culture. Although many luxury products are the same in Asian and Western societies, consumers in said societies might not buy these products for the same reasons (Wong and Ahuvia,1998). If this is the case the question does arise whether it is reasonable to apply theories and concepts tested in other countries and cultures to Sri Lankan perspective, given the fact that Sri Lanka is different from other countries in the Asian region with higher socio-economic 
levels and having different ethnic groups. It was further noted that very few cross-cultural studies have been undertaken under this area. However, the limited findings suggest that the theories are not equally effective in different cultures (Bagozzi, Wong, Abe \& Bergami, 2000; Eastman et al., 2019). In addition, it is thought that the customer intention always holds the likelihood of being changed and therefore since it's a dynamic concept, it can constantly be re-evalued by the consumer. This re-evaluation can be triggered by change of situations or circumstances, or as more information related to product choices becomes available. According to Wiedmann \& Hennigs, (2013) strong cross-cultural differences come into focus when evaluating the varied dimensions of luxury through different adjectives. These differences, however, are not defined by the level of maturity of the luxury market in each country, (Wiedmann \& Hennigs, 2013). Numerous researchers have attempted to identify the factors which influence conspicuous consumption. Further previous researchers have stated that there is a moderating effect from cultural orientation towards the relationship between brand association and conspicuous consumption. It was further noted that luxury brands have been initially seen as signaling status for purposes of social comparison (Han, Nunes \& Drèze, 2010). The link between a luxury brand and conveying one's identity extends towards explaining one's personal and cultural values (Ko et al., 2019) as luxury brands have both cultural and personalized meanings (Seo \& BuchananOliver, 2019). The values of luxury consist of luxury for the self and luxury for others (social identity) (Kapferer \& ValetteFlorence, 2018) and exclusivity to differentiate oneself from others (Roux et al., 2017).

Therefore, it is important to understand the brand association and conspicuous buying behaviour patterns and its perspectives in the luxury fashion brand market in the context of Sri Lanka. This study which is a pioneering effort in this regard endeavours to fill the gaps of understanding concerning luxury brand consumption in Sri Lanka.

\section{LITERATURE REVIEW}

\section{Brand Association and Conspicuous Consumption}

Over the last decade, firms have markedly increased their investments in the creation and development of brands. Branding has become a quintessential element in production, distribution, and consumption (Davies \& Ward, 2005). Consumers look for branded products as a point of reference when making purchasing decisions (Sirgy, 1982). Davies \& Ward (2005) asserted that today, there are very few products that remain unbranded, and firms make efforts to associate their brand name with specific and clear values and characteristics that are unique from the competition. Brands are seen as important in creating an identity, a sense of achievement and identification for consumers. Researchers have investigated the value of a brand that stems from the consumer's brand knowledge. Keller (1993) conceptualized brand knowledge as a combination of brand awareness and brand image. To assess the level of consumer's awareness of a brand, both researchers and practitioners have used a brand's recall and recognition. Langer (1997) proposes that brands create value for consumers through potential benefits of recognition and positive feelings among significant others as well as facilitate self-expression. Specific brands can be positioned to maintain exclusivity, to communicate prestige and the social position of the brand user (Zinkhan \& Prenshaw, 1994). It is also evident that certain brand dimensions and associations lead to increased marketplace recognition and economic success as a result of the value consumers place on them (O'Cass \& McEwen, 2004). Brand image is shaped by the associations formed by consumers (Keller, 1993). Brand associations help the consumer process, organize, and retrieve information in memory to aid product choice (Aaker, 1991). Brand associations seen as favorable by consumers provide added value to the brand by facilitating the formation of strong, positive attitudes and emotions toward the brand (Aaker, 1991). Further certain brands dimensions and associations lead to increased 
marketplace which result in the recognition and economic success for the brand owners. A company's economy superiority is implied by the strength of the brand name and ability to differentiate from its competitors and improve competitiveness (Ocass \& Frost, 2002). This explains the significance of brands and the need to understand how brands gain status, success and value. Further customer attention has shifted to their consumption of status brands (bell et al., 1991; Eastman et al., 1999; Underwood, 1994). Certain research has focused on how consumers are most likely to use status brands in their lives and the status that comes from displaying oneself through brands (Eastman et al., 1999; O'Shaughnessy, 1992).

As asserted by Belén del Río, Vázquez \& Iglesias, (2001) there are 2 functions namely social identification function and status function. The social identification function is based on the brand's ability to act as a communication instrument allowing the consumer manifesting the desire to be integrated or, on the contrary, to dissociate himself from the groups of individuals that make up his closest social environment for those people with whom he currently interacts or aspires to do so. Consumers interested in this function will positively value those brands that enjoy a good reputation among the social groups with which they belong to or aspire to be part of (Long \& Shiffman, 2000). The status function expresses the feelings of admiration and prestige that the consumer may experience upon using the brand. According to Vigneron \& Johnson (2004), this function is based on five characteristics of the brand i.e., symbol of the individual's power and social status, reflection of social approval, exclusivity or limitation of the offer to a small number of people, contribution of emotional experiences and technical superiority.

In this way, the status function reveals the need of individuals to communicate certain impressions to people in their social environment. However, the difference between the two functions lies in the fact that the social identification function is related to the desire to be accepted by and feel camaraderie with members of certain groups. On the other hand, the status function corresponds to the individual's desire to achieve prestige and recognition from others, without this necessarily meaning that the brand is representative of their social group. Therefore, the status could conflict with and impede the individual's identification with certain social groups.

This implies that the status and conspicuous consumption tendencies of consumers are important in creating relationships between consumers who possess such characteristics and specific types of products and brands that yield status. Goldsmith et al. (1996) assert that 'one important motivating force that influences a wide range of consumer behaviour is the desire to gain status or social prestige from the acquisition and consumption of goods.' Inherently, 'the more a consumer seeks status, the more consumer will engage in behaviours, such as the consumption of status symbols, that increase their status' (Eastman et al., 1999). It has been argued that ownership of specific products or brands, as well as their particular mode of consumption, may represent status (McCraken, 1988; O'Shaughnessy, 1992; Packard, 1959; Bell et al., 1991). The desire for status is not exclusively limited to the wealthy (Ram, 1994; Underwood, 1994) and it may be that outward symbols of status are meaningful to both the rich as well as those of modest means (Bansanko, 1995). It has also been argued by Belk (1988) that, even in developing countries people are often attracted to and indulge in aspects of conspicuous consumption before they have adequate basic needs such as food, clothing and shelter. While clearly labelling this as conspicuousness, the implication is that consumers at every class level have the desire to consume for social status. In saying this, it must be recognized that status symbols vary depending on social class, age and gender, and each may have different perceptions of status symbols (O'Cass \& McEwen, 2004).

Further, researchers have found that brand associations have a positive influence on 
consumer choice, preferences and intention of purchase. It encompasses their willingness to pay a price premium for the brand, accept brand extensions and recommend the brand to others (Park \& Srinivasan, 1994; Hutton, 1997; Yoo et al., 2000). As per Shukla (2008) there is a strong significant relationship between conspicuous consumption, psychological antecedents and brand antecedents. This is further connected with the extension of positive relationships between psychological and brand antecedents pertaining especially with conspicuous consumption among the middle-aged consumers. Overall, this study makes two major contributions to the literature related to conspicuous consumption: i.e it validates the strong contribution of psychological antecedent and brand antecedent as determinants of conspicuous consumption.

According to the above literature, it was noted that there is no commonly agreed dimension or model for brand association. Different researchers have used different dimensions for their studies. As previously noted, Aaker (1991) defines brand associations as anything linked in memory to a brand. Three related constructs that are, by definition, linked in memory to a brand, and which have been researched conceptually and measured empirically, are brand image, brand attitude, and perceived quality. As such this study will consider these three constructs as possible dimensions or indicators of brand associations in the conceptual framework.

\section{Measurement Scale for Brand Association}

It is important for the marketers to measure consumer tendencies in order to come up with the right marketing strategy. Hence, we need reliable and valid scales to identify consumer propensity. There were few measurement scales from different product categories were found from previous literature. However, the researcher has considered 2 scales for brand image. i.e. Brand Origin and Brand Image Scale developed by Batra et al, (2000) and adopted 2 items from this scale for the present study. This scale tested among consumers in developing countries, brands perceived as having a nonlocal country of origin, especially from the West, are attitudinally preferred to brands seen as local, for reasons not only of perceived quality but also of social status. Further The researcher considered items from 2 scales for Brand attitude construct i.e. 3 items from Brand Attitude Scale of Sengupta \& Johar (2002) and 6 items from Attitude toward private-label brands scale of Burton et al., (1998). The reliability and the validity of the items adopted from Brand Attitude Scale of Sengupta \& Johar (2002) were above the accepted levels and can be used for the present research context. Further, 6 items from Attitude toward private-label brands scale of Burton et al., (1998) was adopted for the present study. In addition, the researcher is under the opinion that the study should adopt 8 items from Brand Luxury Index Scale (Erdogmus \& Budeyri-Turan, 2012) for perceived quality indicator given the fact that the Alpha value is 0.93 which is above the accepted levels of reliability. This study presented a brand loyalty model for the readyto-wear industry and tested it on generation Y consumers.

\section{Moderating Effect of Personal Cultural Orientation towards the relationship between brand Association and Conspicuous Consumption}

A culture has long been identified as a key environmental characteristic underlying systematic difference in behavior. Cultural norms and beliefs are powerful forces shaping people's perceptions, dispositions, and behaviors (Markus \& Kitayama, 1991). The failure to consider cultural differences between countries into account, has been the cause of many business failures (Ricks, 1993). Moreover, many of our marketing theories have been developed and validated only in Western countries, particularly the USA. Further advancement of marketing as an academic discipline requires that validity of our theories and models be examined in other cultural settings. This will serve to identify the degree of generalizability of these theories and to unravel and explain further details pertaining to boundary conditions (Steenkamp, 2001). 
Consumer attitudes are originated from their values, and therefore are closely interconnected and associated with culture. Value is the core element of culture (Hofstede, 2001). Culture has a pervasive influence on consumer behavior (Craig \& Douglas, 2006; Tascioglu, Eastman, \& Iyer, 2017). Hofstede (2013) has described culture as the means of identifying and differentiating members of a group from others based on the collective programming of the mind. Diverse marketing literature has clearly demonstrated that cultural variables can impact consumers (Craig \& Douglas, 2006), but that culture is dynamic and no longer delineated by the concept of nation (Craig \& Douglas, 2006). Thus, there is a global consumer culture with consumers within a nation becoming more culturally heterogeneous (Carpenter, Moore, Doherty, \& Alexander, 2012). Hofstede (1980, 1983) suggests a series of criteria and dimensions that could be used to help describe the nature of a national culture. Five of those cultural dimensions are as follows; individualism, collectivism, masculinity, long-term orientation, power distance, and uncertainty avoidance. These have been explored in research. Researchers believe that cultural and ethnic groups influence consumer values, attitudes and behavior, including attitudes regarding status and psychological needs. Luxury consumption is far more supported by culture in countries which have strong cultural orientation (Wiedmann \& Hennigs, 2013). Many recent studies point at the necessity of adapting branding and advertising strategies to the culture of the consumer. In order to understand cultural differences, several models have been developed out of which the Hofstede model is the most used. (Mooij \& Hofstede, 2010) Geert Hofstede's dimensional model of national culture has been applied to various areas of global branding and advertising, and for best comprehending the underlying theories of consumer behaviour. Hofstede's dimensional model has been further used to explain differences of the concepts of self, personality and identity, which in turn explain variations in branding strategy and communications (Mooij \&
Hofstede, 2010). Han \& Zhou (2002) proposed an integrative model, and argued that three variables, namely Country-of-Origin, Brand Name, and Price, were major predictors for overall product evaluation and purchase intentions. According to Han \& Zhou's (2002) model, except for the price factor, consumers have keen eagerness for a product's brand name as well as Country-of-Origin, regardless of their culture, status, or psychological needs. As a result, luxury commodities are typically regarded as rational and conspicuous consumption. Wong \& Ahuvia (1998) indicated that many luxury products are the same in Asian and Western societies, but that consumers in different societies might not buy the products for the same reasons. Empirical research has shown that consumers in collectivist cultures have a different attitudinal and perception-based approach toward luxury brands that differ from those of consumers in individualist societies (Wong \& Ahuvia, 1998). The summing up of this could mean that behavior is driven by attitudes and McAleer \& Mao (2016) concluded that in a highly collectivist country, consumers may buy luxury goods to gain external social status. Here is a comparison of the Hofstede analysis for Sri Lanka. Accordingly, Sri Lanka indicates a high level of inequality of power and wealth within the society and has Power Distance (PDI) as the highest Hofstede Dimension for culture, with a ranking of 80 compared to a world average of 56.5. Sri Lanka's Long-Term Orientation (LTO) Dimension rank is 45 , with the world average at 48 which is slightly below the world's average. Sri Lanka has Masculinity ranking Hofstede Dimension at 10, with the world average is at 51 which is very lowest compared to world's ranking. A higher score on masculinity would stand for a greater the gap between values of men and women given the fact that Sri Lanka is male dominated country thus a low value. Sri Lanka's ranking dimension of Uncertainty Avoidance (UAI) at 45 , compared to the world average of 65 . As such, the culture may be more open to unstructured ideas and situations. To take this further, this also indicates a mindset open to 
new ideas. However, there are evidence that even within one country, cultural variables can play a role in influencing the relationship of motivation and purchase intention. Eastman et al., (2018) found support that collectivism, uncertainty avoidance, power distance, and masculinity drive the relationship between status motivations and luxury fashion purchase intention (Eastman et al., 2018). Hofstede's work on national culture has been examines the individual perspective to better understand how culture impacts consumers at the individual level (Lam, Lee, \& Mizerski, 2009; Yoo, Donthu, \& Lenartowicz, 2011).

Since there are mixed findings in the above literature and no common agreement among the previous studies regarding the context, further studies have been conducted in different backdrops but there is potential for more research findings to bridge the literature gap. In addition, as per previous literature, it was noted that the variables considered for the present study has not been empirically tested in an integrated model proposed by the researcher in the conceptual framework under the context of luxury fashion brand market in Sri Lanka. Therefore, this study aims to fill aforesaid empirical gap.

\section{Measurement Scale for Personal Cultural Orientation}

Most previous research on cross-cultural consumer behavior and international business was based on the presumption that Hofstede's dimensions of national culture can be applicable even at an individual level. However, it can lead to 'ecological fallacy' as termed by (Bond 2002). These studies simply used the nation scores on Hofstede's factors to predict cross-cultural differences in consumer attitudes and behavior (e.g., Albers-Miller \& Gelb 1996; Birgelen et al. 2002; Laroche et al.2004; Sivakumar \& Nakata 2001; Steenkamp et al. 1999). However, nation-level generalization may not fully represent the diversity in the cultural orientations of the citizens of a country as a whole since they may not all possess the same percentage of their national cultural characteristics (Bond 2002; Hofstede 1991; Leung 1989). Further,
Oyserman et al. (2002) argued that the human mind may think in both ways; national as well as individual, depending on the situational requirements. Moreover, Blodgett et al. 2008 asserted that several non-cultural factors which are not controlled in many of these studies, may provide an alternative explanation for the differences between samples from diverse countries (Blodgett et al. 2006).

Furthermore, Hofstede's 32-item original scale also lacks sufficient construct validity when applied to an individual context (Blodgett et al. 2008). Similar concerns exist about the construct validity and reliability of Hofstede's (1994) Values Survey Module (Spector et al. 2001). Hence, using nation-level scores on Hofstede's cultural dimensions to predict consumer behavior may pose problems (Bearden et al. 2006). It was noted that some studies have used a few items from Hofstede's original 32-item scale and his VSM 94 scales reflecting work related values (Eg. Dorfman \& Howell 1988; Erdem et al. 2006; Furrer et al. 2000; Hui 1988; Jung \& Kellaris 2006; Lee \& Lim 2008) and noted that these studies have not provided any evidence of the content or construct validity of these reduced or adopted scales. The same was applicable for the crosscultural measurement equivalence across samples drawn from different countries (Sharma, 2009).

The Cultural Value Scale (CVSCALE) has assessed the Hofstede's five dimensions of culture at the individual level and also considered items from non-Hofstede works to carry the core meanings of the constructs as defined by Hofstede (Boonghee Yoo, Naveen Donthu \& Tomasz Lenartowicz, 2011). The CVSCALE was psychometrically sound, ensuring the validity, reliability, and crosscultural measurement equilibrium. This would be a scale that measures Hofstede's five cultural dimensions at the individual level for a broader generalized context while achieving satisfactory psychometric properties (Boonghee Yoo, Naveen Donthu \& Tomasz Lenartowicz ,2011). Further personal values are imbedded into this scale and which is reflected in the theoretical framework of the 
present study. Since the cross-cultural literature suggests that age, gender, and marital status may affect measures of cultural orientations (Lenartowicz and Roth, 1999), CV Scale tested these variables for a determination of the relevant influence (Donthu and Yoo 1998). This scale has been most popular and reliable in consumer behavior context(Patterson et al. 2006; Soares et al. 2007; Yoo \& Donthu 2005), Further this scale has been used in the study areas of Effective service recovery programs (Patterson et al., 2006), service quality expectations (Donthu and Yoo, 1998), marketing ethics (Paul et al., 2006; Yoo and Donthu, 2002), consumer ethnocentrism (Yoo and Donthu, 2005), monetary promotions (Smith, 2004), sales manager and salesperson relationships (Kwok and Uncles, 2005), customer participation on value creation (Chan et al., 2010), adoption of internet shopping (Adapa, 2008), and word-of-mouth referral in relational service exchange (Schumann et al., 2010).

At the time of validating this scale, the questionnaire was administered to undergraduate college students of the U.S. to finalize the wording. Participation was made optional. A total of 196 participants reviewed the items and the wording of the items modified based on participants' suggestions to enhance validity and clarity in meaning. After eliminating redundant items, 86 newly worded items were administered to another sample of 116 American undergraduate students to obtain items which provide decent reliability. After a series of item selection procedures, satisfactory reliability, ranging from .74 to .91 , was achieved for the cultural dimensions. Total retained 39 items to enter the main scale development process. CV SCALE surveyed American, Korean American, and South Korean undergraduate students in an effort to develop a scale with cross cultural generalizability.

Among all these scales, the Cultural Value Scale (CV SCALE) (Donthu \& Yoo 1998) seems most popular and reliable (Patterson et al. 2006; Soares et al. 2007; Yoo \& Donthu 2005). Based on this evidence the researcher considered the cultural Value scale for the present study. However, Eastman et al., (2018) supported the view that collectivism, power distance, and masculinity drive the relationship between status motivations and luxury fashion purchase intention (Eastman et al., 2018) and the same evidence was supported by many other researches too. Hence the researcher adopted only these constructs for the present study. In addition, Cultural Value SCALE (CVSCALE) (Donthu and Yoo 1998) measures one dimension, for an example the collectivism dimension and treats individualism as its opposite. Thus, the same base is being applied for the present study. Accordingly, following conceptual framework is proposed for the present study.

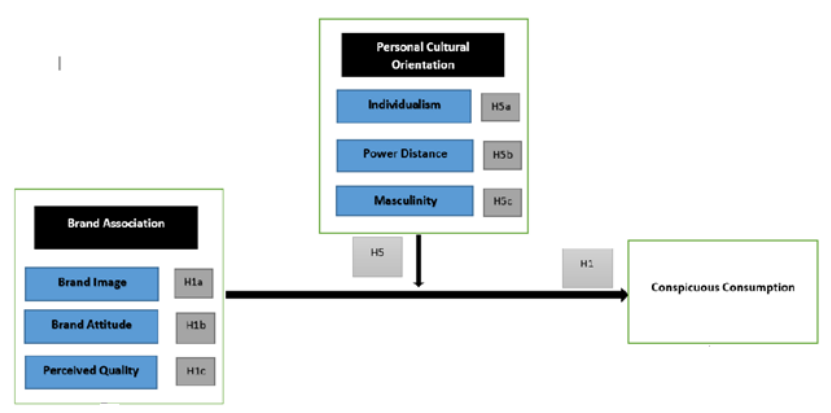

Figure 1: Conceptual Framework

Based on the previous literature, the most appropriate measurement scales were identified and justification for the consideration of them for the present study were discussed in detailed in the above sections. Based on these grounds, the researcher has proposed the above conceptual framework for this study.

\section{Hypotheses Development}

As per the details discussed in above sections, several researchers have investigated the relationship between brand association and Conspicuous Consumption. (Park et al. ,1986: O'Cass \& Frost, 2002: Shukla,2008: Shukla ,2010: Roy \& Rabbanee, 2015). Further brand association has been analyzed under several dimensions such as brand symbolism (Park et al.,1986; O’Cass \& Frost, 2002), Self-concept 
\& Brand Image congruency (O'Cass \& Frost, 2002; Roy \& Rabbanee, 2015), Brand familiarity (Flynn \& Goldsmith, 1999; O'Cass \& Frost, 2002) and Brand arose feelings (Gardner, 1985: Chaudhuri, 1997; O’Cass \& Frost, 2002; Agarwal \& Malhotra, 2005).

Based on above, the authors propose the following hypothesis.

H1: There is a positive influence of Brand Association on Conspicuous Consumption behavior in the luxury fashion brands market.

Consumer attitudes are derived from their values, and hence are closely interconnected with culture (Mooij, 2004). Value is the core element of culture (Hofstede, 2001). Hofstede $(1980,1983)$ suggests a series of dimensions that could be used to help describe the nature of a national culture. Five of those cultural dimensions, individualism-collectivism, masculinity, long-term orientation, power distance, and uncertainty avoidance are explored in this research. As per the details given in the chapter 02 , it was also noted that the personal cultural orientation has a moderating impact on the relationship between brand association and conspicuous consumption based on previous literature (Hofstede, 1981; Hofstede, 1983; Craig \& Douglas, 2006; Hofstede, 2001; Hofstede, 2011; Hofstede, 2013; Mooij, 2004; Mooij \& Hofstede, 2010; Wiedmann \& Hennigs, 2013; Wong \& Ahuvia, 1998).

Based on above, the authors propose the following hypothesis.

H2: Personal Cultural orientation moderates the relationship between Brand Association and Conspicuous Consumption in the luxury fashion brands market in Sri Lanka.

\section{RESEARCH METHOD}

As the present study was designed based on deductive approach in positivist research paradigm, conceptual framework and hypotheses were developed based on sound theoretical and literature background. As survey method was adopted to primary data collection, researcher administrated questionnaire was employed as the research instrument. The target population for the study is defined as "the global middle-class population who are spending (PPP) more than $10 \$$ and less than $100 \$$ a day per capita and the rich upper-class population who spends more than $100 \$$ a day per capita" Accordingly, the researchers initially defined the target population and estimated the size of the sample unit. Further, it was decided the appropriate sample size 384 based on the Cochran's sample size estimating formula which is commonly used in marketing research (Bartlett et. al., 2001). The researcher decided to increase the sample size beyond the required limit with the purpose of increasing the validity of generalization in the findings. Accordingly, the sample size was further modified based on its contingency effect and estimated response rate (Bartlett et. al., 2001). According to Bartlett et. al., (2001), contingency effect means the possible number of rejected questionnaires due to response or recording error. Therefore, the minimum sample size was increased by $10 \%$ and new sample size was decided as $461(384 * 110 / 100)$. As data collecting methods include online survey, it was estimated $50 \%$ as non-responsive rate. Therefore, the final sample size was 634 respondents $(422 * 150 / 100)$.

The researcher selected a multilevel mixed method of sampling as a most practical approach for selecting samples to the present study. Accordingly, the sample selecting process consists of three levels.

Further, several measurement indicators were identified to assess each variable of the conceptual framework. Therefore, the selected indicators were validated by other researchers in many socio-economic contexts with an accepted level of reliability which is more than 0.70 alpha. As data collection was done through administrated questionnaire and 12 districts were included into the sample, it was decided to administrate the questionnaires by well experienced enumerators. Altogether 634 questionnaires were administrated and 398 
questionnaires were considered for the data analysis due to incomplete cases, some missing values and extreme cases.

Further, it was noted that $81.9 \%$ of the sample representation of the present study is from the global middle class while balance $18.1 \%$ represent the rich upper class of the country. The sample consisted of both males $(54 \%)$ and females $(46 \%)$ and higher proportion represent 34 to 41 age category $(37.7 \%)$. $75.1 \%$ of the sample represent married people whereas $22.9 \%$ are still single. The above findings revealed that the employment type of the sample consist of $23.4 \%$ of entrepreneurs, $60.3 \%$ of professionals, and $14.1 \%$ of selfemployed respondents. it was noted that $37.7 \%$ of the sample representation were graduates and $37.2 \%$ are postgraduates hence having a good education background. This finding is consistent with the previous studies in Asian countries where people with higher educational background are having more conspicuous consumption behavior. $35.9 \%$ of the sample representation has a monthly income of more than Rs. 750,000. Further $35.4 \%$ earn a monthly income of Rs. 550,000 to 750,000 whereas $20.1 \%$ earns more than Rs. 350,000 to 550,000 a month. Therefore, the demographic profile of the sample was reasonably representing the target population of the given study and it is sufficient to analyze the research issue of the given context.

\section{FINDINGS AND DISCUSSION}

The IBM SPSS 23 package was employed for initial data analysis. Firstly, a reliability analysis was conducted to determine the internal consistencies of each scale adopted to measure the concept through Cronbach's Alpha Coefficients. Further, descriptive statistics were calculated to measure the degree of personal cultural orientation, brand association and conspicuous consumption in the given research context. The results are summarized in the table 01 .
TABLE 01: Results of Reliability Test

\begin{tabular}{|l|l|l|l|l|}
\hline Dimension & $\begin{array}{l}\text { No. } \\
\text { of } \\
\text { item }\end{array}$ & $\begin{array}{l}\text { Cronbach's } \\
\text { alpha }\end{array}$ & Mean & SD \\
\hline $\begin{array}{l}\text { Individualism } \\
\text { (IN) }\end{array}$ & 06 & 0.893 & 4.6310 & 1.27687 \\
\hline $\begin{array}{l}\text { Power } \\
\text { Distance } \\
\text { (PD) }\end{array}$ & 04 & 0.738 & 4.1690 & 1.64426 \\
\hline $\begin{array}{l}\text { Masculinity } \\
\text { (MU) }\end{array}$ & 04 & 0.9 & 3.9388 & 1.06774 \\
\hline $\begin{array}{l}\text { Brand } \\
\text { Association }\end{array}$ & 21 & 0.751 & 5.4397 & 0.57836 \\
\hline $\begin{array}{l}\text { Conspicuous } \\
\text { Consumption }\end{array}$ & 06 & 0.756 & 5.1018 & 1.21357 \\
\hline
\end{tabular}

Source: Survey data 2020

According to the reliability statistics given in the table 1 , the reliabilities of all scales are found to be adequate since Cronbach's Alpha values are higher than 0.7 . The mean value of brand association is at a higher level which is at $5.4397(\mathrm{M}=5.4397, \mathrm{SD}=0.57836)$. The mean value of conspicuous buying behavior is at a higher level which is at 5.1018 (M= $5.1018, \mathrm{SD}=1.21357)$. Further, the mean value of individualism and power distance is at a higher level which is at 4.631 and 4.169 respectively. $(\mathrm{M}=4.631, \mathrm{SD}=1.27687$, $\mathrm{M}=4.1690, \mathrm{SD}=1.64426)$. When considered the masculinity, the mean value is reported below the average which is at 3.9388 since the neutral point is at $4(\mathrm{M}=3.9388, \mathrm{SD}=$ 0.1.06774) which is not in line with the research findings of western countries. Therefore, the researcher can argue that the people who have conspicuous buying behavior is much different to the people who have similar buying behavior in other parts of the world.

PLS-SEM was employed as the main measurement model for the present study. The researchers employed the Smart-PLS 3 as the main analytical software due to the reflective in nature of the latent variables in the conceptual model. Initially, it was tested in theoretical and literature perspective and then it was statistically justified by confirmatory 
tetrad analysis (CTA). According to the findings of CTA, brand association was recognized as a reflective latent variable in the present model. It was further confirmed that LOCs (Lower Order Constructs) of brand association and personal cultural orientation. Further conspicuous consumption too can be considered as reflective latent variables in the present conceptual model. Therefore, measurement model assessments criteria should be tested separately to each variable categories based on CTA.

The present model was assessed based on two stage approach. Based on all the considerations, initially direct relationship between the brand association and conspicuous consumption was tested and results are summarized into figure 2 and table 2.

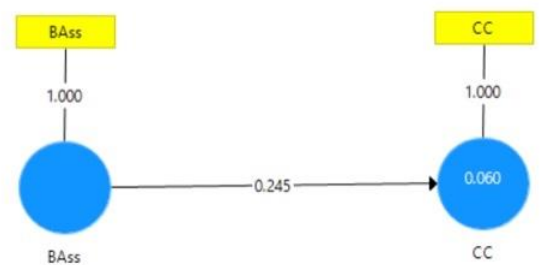

Figure 2: Direct relationship between Brand Association (BAss) and Conspicuous Consumption (CC)

TABLE 2: Significance of the Direct Relationship between BAss and CC

\begin{tabular}{|c|c|c|c|c|c|c|c|c|}
\hline 詰 & $\infty$ & 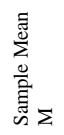 & $\begin{array}{l}\text { 㟔 } \\
\text { 离 }\end{array}$ & 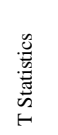 & 岁 & $\stackrel{\mathscr{f}}{\tilde{m}}$ & 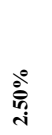 & $\begin{array}{l}\stackrel{\circ}{\circ} \\
\text { "ू. }\end{array}$ \\
\hline $\begin{array}{l}\text { BAss - } \\
>\text { CCC }\end{array}$ & 0.245 & 0.243 & 0.062 & 3.921 & 0.000 & 0 & 0.12 & \\
\hline
\end{tabular}

Source: Survey Data, 2020

Direct relationship is assured based on significant path coefficients $(b=0.245, \quad t$ $=3.921, \mathrm{p}=0.000$ ), with acceptable range of $\mathrm{BCa}$ confidence intervals (lower $=0.12$ and upper $=0.362$ ). Further, determinant of coefficient is given in the figure 2, 6\% of conspicuous consumption is represented by brand association in the luxury fashion brand market in Sri Lanka. Therefore, $\mathrm{H1}$ is empirically supported in the present research context.

\section{H2: Personal Cultural Orientation moderates the relationship between Brand Association and Conspicuous Consumption in the luxury fashion brands market.}

Moderation describes a situation in which the relationship between two constructs is not constant but depends on the values of a third variable, referred to as a moderator variable Hair et al., (2017). The moderator variable changes the strength or even the direction of a relationship between two constructs in the model. In many situations, researchers have a continuous moderator variable they believe can affect the strength of one specific relationship between two latent variables. In the present study the moderator is personal cultural orientation which is a continuous variable. Many research have proposed several approaches for creating the interaction term (Henseler \& Chin, 2010; Henseler \& Fassott, 2010; Brijwani, Rigdon \& Vadlani, 2010). However, Hair et al., (2017) suggested three approaches i.e. the product indicator approach, the orthogonalizing approach, and the twostage approach. The product indicator approach is the standard approach for creating the interaction term in regression-based analyses and also features prominently in PLSSEM. Hair et al., (2017) suggested if the model of study is of a reflective nature, to choose the product indicator approach. Hence the researcher opted for the product indicator approach for the present study.

In addition, measurement and structural model evaluation criteria, also apply to moderator models. When assessing reflective measurement models, the moderator variable must meet all relevant criteria in terms of internal consistency reliability, convergent validity, and discriminant validity if it is a continuous variable (Hair et al., 2017). Finally, it is also important to consider the standard criteria for structural model assessment. In the context of moderation, particular attention should be paid to the $\mathrm{f} 2$ effect size of the interaction effect. 
As per the findings, it was revealed that Cronbach's alpha values of all variables are above the threshold level. Thus, the reliability of all the variables are assured. In addition, rho_A and Composite Reliability values of each measurement scale were reported more than 0.7 which is the rule of thumb. Further to evaluate the convergent validity of reflective constructs, researchers consider the outer loadings of the indicators and the average variance extracted (AVE) (Hair et al., (2017). AVE indicates the average communality of latent variable in the measurement model and the value should be greater than 0.5 (Partanen et al., 2017; Hair et al., 2018). As per the above table, the values are well above 0.5 . As such it assures the internal consistency and convergent validity of all the measures of the variables in the present model. Further, the recommended threshold in HTMT is less than 0.90 (Henseler, Ringle and Sarstedt, 2015). The present study used a bootstrapping procedure to determine whether the HTMT value is statistically significantly lower than one (Hair et al., 2017; Ringle et al.,2018) According to the results, discriminant validity of the model is also assured. Further to the above discussion it was noted that the criterion for reliability and validity is met based on the recommended threshold. Accordingly, the next step would be assessing the size of the moderating effect.

When assessing the size of the moderating effect, according to the figure 3 below, the interaction term has a negative effect on conspicuous consumption (-0.431), whereas the direct effect of brand association on conspicuous consumption is 0.119 . Therefore, we can conclude as a moderator that personal cultural orientation has a significant moderating effect on brand association and conspicuous consumption.

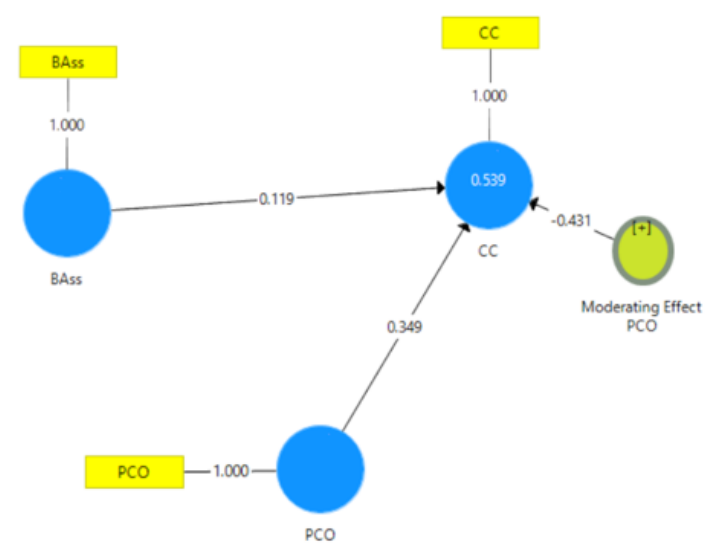

Figure 3: Moderator Analysis Outcome of SmartPLS

Source: Survey Data, 2020

When there is a significant moderation, the next step would be to determine the strength of the moderating effect. Please refer the below calculation for the change of the direct relationship with moderator change in both higher and lower levels.

\section{Higher level of PCO,}

Change of BAss $->\mathrm{CC}=$ Coefficient of direct effect + Interaction term $=0.119+(-0.431)=-$ 0.312

This can be interpreted that if PCO is increased by one stranded deviation unit, the relationship of BAss and $\mathrm{CC}$ is increased by -0.312 units.

\section{Lower level of PCO,}

Change of the BAss $->\mathrm{CC}=$ Coefficient of direct effect - Interaction term $=0.119-(-$ $0.431)=0.55$

This can be interpreted that if PCO is decreased by one stranded deviation unit, the relationship of BAss and CC stands decreased by 0.550 units. Therefore, it was noted that, PCO moderates the relationship between Brand Association (BAss) and Conspicuous consumption (CC). Further, Hair et al., 2017 suggested to perform a slope plot as this was the common way of illustrating the results of a moderation analysis. 
The below figure 4, display the simple slope plot in SmartPLS outcome. It was noted that there are 3 lines shown in the given slope plot in figure 4. They represent the relationship between BAss and CC. The middle line represents the relationship for an average level of the moderator variable PCO. The other two lines represent the relationship between BAss and $\mathrm{CC}$ for higher (which means mean value of $\mathrm{PCO}+$ one standard deviation unit) and the $2^{\text {nd }}$ line represent the lower which significes the mean value of PCO - one standard deviation unit) levels of the moderator variable PCO. As we can see, the relationship between BAss and CC is positive for all three lines as indicated by their positive slope. Hence, there is a moderator effect for the relationship between Brand Association and Conspicuous Consumption.

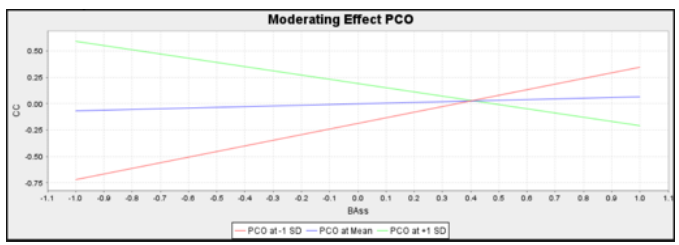

SD - Standard Deviation

Figure 4; Slope plot of moderator PCO

Source: Survey data, 2020

In addition, Hair et al., 2017 suggested to analyze the moderating effect's slope in greater detail. The upper line, which represents a high level of the moderator construct PCO, has a flatter slope while the lower line, which represents a low level of the moderator construct PCO, has a steeper slope. This makes sense since the interaction effect is negative. As a rule of thumb and an approximation, the slope of the high level of the moderator construct PCO is the simple effect i.e., 0.119+ the interaction effect $(-0.431)$, while the slope of the low level of the moderator construct SC is the simple effect i.e., 0.119 - the interaction effect $(-0.431)$. Hence, the simple slope plot supports our previous discussion of the negative interaction term: Higher PCO levels entail a weaker relationship between BAss and $\mathrm{CC}$, while lower levels of PCO lead to a stronger relationship between BAss and CC.
As the next step, Hair et al., 2017 suggested to assess the significance of interaction term.

The next step would be to assess the significance of the interaction term. Hair et al., 2017 suggested to run the bootstrapping procedure with 5000 bootstrap samples using the no sign change option in PLS. Figure 5 display the bootstrapping results of the moderator analysis.

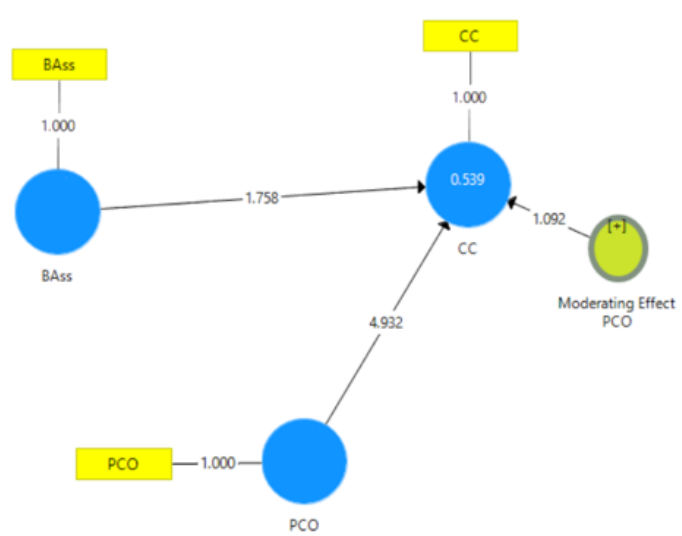

Figure 5; Bootstrapping Results of the Moderator Analysis

Source: Survey Data, 2020

The analysis yields at value of 1.092 for the path linking the interaction term and CC (Figure 5). Similarly, the 95\% bias-corrected bootstrap confidence interval of the interaction term's effect is $[0.457,0.64]$. As the confidence interval does not include zero, we conclude that the effect is significant. Overall, these results provide clear support that PCO exerts a significant and negative effect on the relationship between BAss and CC.

To conclude the results presentation, the final step addresses the moderator's $f^{2}$ effect size. In the PLS algorithm, the interaction terms $\mathrm{f}^{2}$ effective size has a value of 0.150 . According to Kenny (2016), value indicates a large effect.

In summary, the moderator impact is analyzed as per the recommended criterion by Hair et al., 2017 and it is revealed that PCO moderates the relationship between the Brand Association and Conspicuous consumption. Accordingly, it is confirmed that $\mathrm{H} 5$ is 
accepted. In summery, these findings will support decision makers to make strategic decision on marketing communication.

\section{CONCLUSION AND FUTURE RESEARCH DIRECTIONS}

In accordance with the empirical results given in above, the selected variables in the conceptual framework can be applied to measure brand association, personal cultural orientation and conspicuous consumption in the present research context. Further, reliability statistics revealed that all scales are reliable to determine the degree of those concepts in conspicuous consumption in the luxury market segment in Sri Lanka. The descriptive statistics emphasize the present degree of each concept in the present context. Accordingly, The mean value of brand association, conspicuous consumption, individualism and power distance was at a higher level, however the mean value of masculinity is reported below the average. Further, the results assured the direct relationship between brand association and conspicuous consumption.

It was noted that the personal cultural orientation has a moderating impact on the relationship between brand association and conspicuous consumption based on the previous literature (Hofstede, 1981; Hofstede, 1983; Craig \& Douglas, 2006; Hofstede, 2001; Hofstede, 2011; Hofstede, 2013; Mooij, 2004; Mooij \& Hofstede, 2010; Wiedmann \& Hennigs, 2013; Wong \& Ahuvia, 1998). However, Eastman et al., (2018) suggested that individualism, power distance, and masculinity moderate the relationship between status motivations and luxury fashion purchase intention (Eastman et al., 2018) and same evidence was supported by many other research too. Since the present study is in the same context, the researcher adopted only these constructs for the study.

Accordingly, the moderator PCO and it's dimensions were tested based on measurement and structural model evaluation criteria, which apply to moderator models. When assessing reflective measurement models, the moderator variable must meet all relevant criteria in terms of internal consistency reliability, convergent validity, and discriminant validity if it is a continuous variable (Hair et al., 2017). In addition, it is also important to consider the standard criteria for structural model assessment. Further, considerable attention should be paid to the $\mathrm{f}^{2}$ effect size of the interaction effect. As such, the analysis yields a $t$ value of 1.092 for the path linking the interaction term and CC. Similarly, the 95\% bias-corrected bootstrap confidence interval of the interaction term's effect is [0.457, 0.64]. As the confidence interval does not include zero, we conclude that the effect is significant. Overall, these results provide clear support that the PCO exerts a significant and negative effect on the relationship between BAss and CC. To conclude the results representation, the final step addresses the moderator's $\mathrm{f}^{2}$ effect size. In the PLS algorithm, the interaction terms $\mathrm{f}^{2}$ effective size has a value of 0.150 . According to Kenny (2016), value indicates a large effect. Further the slope plot shows a significant moderation both at higher and lower level towards the conspicuous consumption. Thus, the findings of the present study supported that PCO has a significant negative moderation towards the relationship between brand association and conspicuous consumption. In addition, especially in the Sri Lankan context, the researcher could not find any research in published sources focus on the moderation effect of the PCO with the relationship between BAss and CC. Therefore, the present research successfully bridges an important gap in the literature by positioning the moderation effect of PCO. Theoretically, the present study further confirms an extension to theory of conspicuous consumption. Hence the present study would fulfill the theoretical gap up to considerable level in the luxury fashion brand market in Sri Lanka.Therefore, these findings will support decision makers to make strategic decision on marketing communication.

It is vital that firms of luxury products and brands should learn how best to market their luxury goods and services whether a new 
luxury product is being created with the view of a "right" type of consumer in mind; or when an existing product is being repositioned in the actual battlefield of the demanding contemporary luxury market as once a conspicuous product loses its cache, it is extremely difficult for that firm to recover (Eastman et al., 2018: Eastman, 1999). Thus, the importance of properly marketing conspicuous products cannot be overemphasized. As discussed in this study the social status and social motives are the distinctive factors that drive people to luxury consumption.

Products and brands are an important way consumer reflect or shape their identities. When individuals review marketing prospects, the fact that the brand image goes in line with their personal image is a critical consideration which leads to purchase intention. Further the consumer develops emotional and personal connections to that product or the brand. Further the meaning of symbols attached to products should be culturally bound and they can convey important information of an individual. When shaping the buying process, it is important to understand the perceptions and attitudes of the consumers regarding luxury brands. This is especially so in a country like Sri Lanka where culture plays a major role towards purchases intention. As per the findings of the study it was noted that the personal cultural orientation has a significant moderating impact towards the relationship between brand association and conspicuous consumption in the luxury fashion brand market. Hence the decision makers and marketers should consider common values of Sri Lankan culture as a main aspect of brand architectures. Further unique cultural values can be associated with market communication where that will add value and bring right attention from the consumers.

Accordingly, the present study offers new knowledge to empirical and theoretical aspects in the context of the luxury fashion brand market in Sri Lanka by further analyzing the impact of dimension of PCO which is a new endeavor in this context in Sri Lanka.
Therefore, the present research successfully bridges an important gap in the literature by positioning the moderation effect of each dimension of PCO. Theoretically, the present study further confirms an extension to the theory of conspicuous consumption. Hence the present study would fulfill the theoretical gap up to considerable level in the luxury fashion brand market in Sri Lanka.

\section{LIMITATIONS AND FUTURE RESEARCH DIRECTIONS}

There are few limitations which offer interesting avenues for further research. Mainly there were 4 areas such as the scope of the study, geographical limitations, sample limitations, methodological limitations within the main confines of the present study which is discussed below.

The product category of luxury fashion brand was chosen more for its popularity and published research in this segment is somewhat limited in this study context in Sri Lankan perspective, however this study can be carried out to other product categories as well. Further, there are 24 districts in the country, however, the present study considered only 14 districts for the data collection as the questionnaire was employed to the loyal card members of the main luxury brand showroom in Sri Lanka. The future research could be carried out covering all district of the country. Further, total population of the present study is approx. 4 million, However, sample size is determined at 634 . Future studies could be conducted with more sample size and results could be different. The present study employed quantitative method to carry out the study based on that the research design adopted. However, given the nature of the study, the context and variables selected, and the target population qualitative approach also can be considered. Further, the researcher considered PLS- SEM for the present study. However, there are other analytical tools too which can be considered. Further personal cultural orientation has many dimensions as per previous studies. However, the present study 
was limited to the 3 dimensions which is more relevant to luxury segment, hence future studies can be extended to those dimensions. However, these limitations do not in any way deface or render less significant the results and findings of the research. They were outlined to acknowledge their existence and to stress the need for further research on the topic.

\section{ACKNOWLEDGMENT}

The authors wish to thank University of Kelaniya, Sri Lanka, which encouraged to publish an article as a partial fulfillment of Doctorate in Business Administration.

\section{REFERENCES}

Aaker, J. (1991). The Negative Attraction Effect? a Study of the Attraction Effect Under Judgment and Choice in NA. Advances In Consumer Research, 18, 462-469.

Agarwal, J., \& Malhotra, N. (2005). An integrated model of attitude and affect. Journal of Business Research, 58(4), 483-493. https://doi.org/10.1016/s01482963(03)00138-3

Albers-Miller, N., \& Gelb, B. (1996). Business Advertising Appeals as a Mirror of Cultural Dimensions: A Study of Eleven Countries. Journal of Advertising, 25(4), 57-70.

https://doi.org/10.1080/00913367.1996.106 73512

Bagozzi, R., Wong, N., Abe, S., \& Bergami, M. (2000). Cultural and Situational Contingencies and the Theory of Reasoned Action: Application to Fast Food Restaurant Consumption. Journal of Consumer Psychology, 9(2), 97-106. doi: 10.1207/s15327663jcp0902_4

Bansanko, D. (1995). The kinder, gentler, richer American. American Demographics, 17(1), 46.

Bartlett, T., Kotrlik, J., \& Higgins, C. (2001). Organizational Research: Determining
Appropriate Sample Size in Survey Research. Information Technology, Learning, And Performance Journal, Vol. 19(1), 43-50. Retrieved from http://citeseerx.ist.psu.edu/viewdoc/downlo ad?doi=10.1.1.486.8295\&rep=rep1\&type $=p$ df

Bearden, W., Money, R., \& Nevins, J. (2006). Multidimensional versus unidimensional measures in assessing national culture values: The Hofstede VSM 94 example. Journal of Business Research, 59(2), 195-203. doi: 10.1016/j.jbusres.2005.04.008

Belén del Río, A., Vázquez, R., \& Iglesias, V. (2001). The effects of brand associations on consumer response. Journal of Consumer Marketing, 18(5), 410-425. https://doi.org/10.1108/0736376011039880 8

Belk, R. (1988). Possessions and the Extended Self. Journal of Consumer Research, 15(2), 139. doi: $10.1086 / 209154$

Bell, S. S., Holbrook, M. B. and Solomon, M. R. (1991) 'Combining esthetic and social value to explain preferences for product styles with incorporation of personality and ensemble effects', in 'To Have Possessions: A Handbook on Ownership and Property', Journal of Social Behaviour and Personality, 6 (6), 243-247.

Blodgett, J., Hill, D., \& Bakir, A. (2006). Cross-cultural complaining behavior? An alternative explanation. . Journal of Consumer Satisfaction, Dissatisfaction and Complaining Behavior, 19(2), 103-117.

Blodgett, J. G., Bakir, A., \& Rose, G. M. (2008). A test of the validity of Hofstede's cultural framework. Journal of consumer marketing.

Brijwani, K., Rigdon, A., \& Vadlani, P. (2010). Fungal Laccases: Production, Function, and Applications in Food Processing. Enzyme Research, 2010, 1-10. doi: 10.4061/2010/149748 
Carpenter, J., Moore, M., Doherty, A., \& Alexander, N. (2012). Acculturation to the global consumer culture: a generational cohort comparison. Journal Of Strategic Marketing, 20(5), 411-423. doi: 10.1080/0965254x.2012.671340

Chaudhuri, A. (1997). Consumption Emotion and Perceived Risk: A Macro-Analytic Approach. Journal of Business Research, 39(2), 81-92. doi: 10.1016/s01482963(96)00144-0

Craig, C., \& Douglas, S. (2006). Beyond national culture: implications of cultural dynamics for consumer research. International Marketing Review, 23(3), 322-342. doi: $10.1108 / 02651330610670479$

Davies, B., \& Ward, P. (2005). Exploring the connections between visual merchandising and retail branding. International Journal Of Retail \& Distribution Management, 33(7), 505-513. doi: 10.1108/09590550510605578

Donthu, N., \& Yoo, B. (1998). Cultural influences on service quality expectations. Journal of service research, 1(2), 178-186.

Eastman, J., \& Eastman, K. (2015). Conceptualizing a model of status consumption theory: An exploration of the antecedents and consequences of the motivation to consume for status. Marketing Management Journal, 25(1), 1-16. Retrieved from http://www.mmaglobal.org/publications/M MJ/MMJ-Issues/2015-Spring/MMJ-2015Spring-Vol25-Issue1-Eastman-Eastmanpp1-15.pdf

Eastman, J., Goldsmith, R., \& Flynn, L. (1999). Status Consumption in Consumer Behavior: Scale Development and Validation. Journal of Marketing Theory and Practice, 7(3), 41-52. doi: 10.1080/10696679.1999.11501839

Eastman, J., Iyer, R., Shepherd, C., Heugel, A., \& Faulk, D. (2018). Do they shop to stand out or fit in? The luxury fashion purchase intentions of young adults. Psychology \&
Marketing, 35(3),

220-236.

doi: 10.1002/mar.21082

Eastman, J., Shin, H., \& Ruhland, K. (2019). The picture of luxury: A comprehensive examination of college student consumers' relationship with luxury brands. Psychology \& Marketing, 37(1), 56-73. doi: 10.1002/mar.21280

Flynn, L., \& Goldsmith, R. (1999). A Short, Reliable Measure of Subjective Knowledge. Journal of Business Research, 46(1), 57-66. doi: 10.1016/s01482963(98)00057-5

Gardner, M. (1985). Mood States and Consumer Behavior: A Critical Review. Journal of Consumer Research, 12(3), 281. doi: 10.1086/208516

Goldsmith, R., Moore, M., \& Beaudoin, P. (1996). Fashion innovativeness and selfconcept: a replication. Journal of Product \& Brand Management, 8(1), 7-18. doi: 10.1108/10610429910257904

Hair, J.F., Hult, G.T.M., Ringle, C.M, (2017). A Primer on Partial Least Squares Structural Equations Modeling (PLS-SEM), Thousand Oaks: SAGE.

Hair, J., Black, W., Babin, B., \& Anderson, R. (2010). Multivariate data analysis (7th ed.). Pearson Prentice Hall.

Hair, J., Hult, G., Ringle, C., Sarstedt, M., \& Thiele, K. (2017). Mirror, mirror on the wall: a comparative evaluation of composite-based structural equation modeling methods. Journal of The Academy of Marketing Science, 45(5), 616-632. doi: 10.1007/s11747-017-0517-x

Hair, J., Ringle, C., \& Sarstedt, M. (2011). PLS-SEM: Indeed a Silver Bullet. Journal of Marketing Theory and Practice, 19(2), 139-152. doi: 10.2753/mtp10696679190202

Hair, J., Ringle, C., \& Sarstedt, M. (2013). Partial Least Squares Structural Equation Modeling: Rigorous Applications, Better Results and Higher Acceptance. Long Range 
Planning, 46(1-2), 1-12. doi: 10.1016/j.lrp.2013.01.001

Hair, J., Sarstedt, M., \& Ringle, C. (2019). Rethinking some of the rethinking of partial least squares. European Journal of Marketing, 53(4), 566-584. doi: 10.1108/ejm-10-2018-0665

Hair, J.F., Sarstedt, M., Ringle, C. M. (2012). An Assessment of the Use of Partial Least Squares Structural Equation Modeling in Marketing Research. Journal of the Academy of Marketing Science 40(3), 414433.

Hair, J.F., Sarstedt, M., Ringle, C.M. (2018). Advanced Issues in Partial Least Squares Structural Equation Modeling (PLS-SEM), Thousand Oaks, CA: Sage.

Hair, J., Anderson, R., Tatham, R., \& Black, W. (1998). Multivariate Data Analysis. Upper Saddle River, NJ,: Prentice-Hall.

Hair, J. F., Black, W. C., Babin, B. J., \& Anderson, R. E. (2009). Multivariate Data Analysis (7 th edition ed.). Chollerstrasse: Prentice Hall.

Han, Y., Nunes, J., \& Drèze, X. (2010). Signaling Status with Luxury Goods: The Role of Brand Prominence. Journal of Marketing, 74(4), 15-30. doi: 10.1509/jmkg.74.4.15

Henseler, J., \& Chin, W. (2010). A Comparison of Approaches for the Analysis of Interaction Effects Between Latent Variables Using Partial Least Squares Path Modeling. Structural Equation Modeling: A Multidisciplinary Journal, 17(1), 82-109. doi: 10.1080/1070551090343900

Henseler, J., \& Fassott, G. (2010). Testing Moderating Effects in PLS Path Models: An Illustration of Available Procedures (pp. 715-735). Springer

Hofstede, G. (1980). Culture's consequences: International differences in work related values. Beverly Hills, CA: Sage.

Hofstede, G. (1983). Culture's Consequences: International Differences in Work-Related
Values. Administrative

Quarterly, 28(4), 625.629

Science $10.2307 / 2393017$

Hofstede, G. (1991). Cultures and organizations: Software of the mind. London: McGraw-Hill.

Hofstede, G. (1994). Value survey module 1994 manual. Maastricht: IRIC, University of Tilburg.

Hofstede, G. (1994). The cultural relativity of the quality of life concept. Academy of Management Review, 9(3), 389-398.

Hofstede, G. (2001). Culture consequences: Comparing values, behaviors, institutions, and organizations across nations (2nd ed.). Thousand Oaks, CA: Sage.

Hofstede, G. (2013). Dimensions of national cultures. Retrieved from https://www.geerthofstede.nl/dimensionsof-national-cultures

Hutton, J. (1997). A study of brand equity in an organizational-buying context. Journal Of Product \& Brand Management, 6(6), 428-439. doi: 10.1108/10610429710190478

Kapferer, J., \& Valette-Florence, P. (2018). The impact of brand penetration and awareness on luxury brand desirability: Journal of Business Research, 83, 38-50. doi: 10.1016/j.jbusres.2017.09.025

Keller, K. (1993). Conceptualizing, Measuring, and Managing Customer-Based Brand Equity. Journal of Marketing, 57(1), 1. doi: $10.2307 / 1252054$

Ko, E., Costello, J., \& Taylor, C. (2019). What is a luxury brand? A new definition and review of the literature. Journal of Business Research, 99, 405-413. doi: 10.1016/j.jbusres.2017.08.023

Langer, J. (1997). What consumers wish brand managers knew. Journal of Advertising Research, Pp. 60-8, 37(6), 60-68.

Long, M., \& Schiffman, L. (2000). Consumption values and relationships: segmenting the market for frequency 
programs. Journal of Consumer Marketing, 17(3), 214-232. doi: $10.1108 / 07363760010329201$

Markus, H., \& Kitayama, S. (1991). Culture and the self: Implications for cognition, emotion, and motivation. Psychological Review, 98(2), 224-253. doi: 10.1037/0033295x.98.2.224

McCraken, G. (1988). Culture and Consumption, Bloomington and Indianapolis, IN. Bloomington and Indianapolis, IN.: Indiana University Press.

O'Cass, A., \& Frost, H. (2002). Status brands: examining the effects of non-product-related brand associations on status and conspicuous consumption Article Options and Tools. Journal of Product \& Brand Management, 11(2), 67-88. doi: http://dx.doi.org/10.1108/10610420210423 455

O'Cass, A., \& McEwen, H. (2004). Exploring consumer status and conspicuous consumption. Journal of Consumer Behaviour, 4(1), 25-39. doi: 10.1002/cb.155

O'Shaughnessy, J. (1992). Explaining buyer behavior. New York: Oxford University Press.

Packard, V. (1959). The Status Seekers. David McKay Co. Inc., New York.

Park, C., Jaworski, B., \& Maclnnis, D. (1986). Strategic Brand Concept-Image Management. Journal of Marketing, 50(4), 135. doi: $10.2307 / 1251291$

Park, C., \& Srinivasan, V. (1994). A SurveyBased Method for Measuring and Understanding Brand Equity and Its Extendibility. Journal of Marketing Research, 31(2), 271-288. doi: $10.1177 / 002224379403100210$

Ramayah, T., Cheah, J., Chuah, F., Ting, H., \& Memon, M. A. (2018). Partial Least Squares Structural Equation Modeling (PLS-SEM) using SmartPLS 3.0: An Updated Guide and Practical Guide to Statistical Analysis (2nd ed.). Kuala Lumpur, Malaysia: Pearson.
Ram, J. (1994) 'Luxury goods firms find a haven in Asia', Asian Business, 30, July, 52-53.

Ricks, D. (1993). Blunders in International Business. Cambridge: Blackwell.

Ringle, C. M., Wende, S., \& Becker, J. M. (2015). SmartPLS 3. SmartPLS GmbH. Boenningstedt. Retrieved from http://www.smartpls.com

Roux, E., Tafani, E., \& Vigneron, F. (2017). Values associated with luxury brand consumption and the role of gender. Journal of Business Research, 71, 102-113. doi: 10.1016/j.jbusres.2016.10.012

Seo, Y., \& Buchanan-Oliver, M. (2019). Constructing a typology of luxury brand consumption practices. Journal of Business Research, 99, 414-421. doi: 10.1016/j.jbusres.2017.09.019

Shukla, P. (2008). Conspicuous consumption among middle age consumers: psychological and brand antecedents. Journal of Product \& Brand Management, 17(1), 25-36. doi: 10.1108/10610420810856495

Shukla, P. (2010). Status consumption in cross-national context. International Marketing Review, 27(1), 108-129. doi: 10.1108/02651331011020429

Sirgy, M. (1985). Using self-congruity and ideal congruity to predict purchase motivation. Journal of Business Research, 13(3), 195-206. doi: 10.1016/0148-2963(85)90026-8

Sirgy, M. (1982). Self-Concept in Consumer Behavior: A Critical Review. Journal of Consumer Research,9(3), 287-300. doi: $10.1086 / 208924$

Sirgy, M., Grewal, D., Mangleburg, T., Park, J., Chon, K., \& Claiborne, C. et al. (1997). Assessing the Predictive Validity of Two Methods of Measuring Self-Image Congruence. Journal of The Academy of Marketing Science, 25(3), 229-241. doi: 10.1177/0092070397253004 
Sirgy, M., Johar, J., Samli, A., \& Claiborne, C. (1991). Self-congruity versus functional congruity: Predictors of consumer behavior. Journal of The Academy of Marketing Science, 19(4), 363-375. doi: $10.1007 / \mathrm{bf02726512}$

Sirgy, M., \& Su, C. (2000). Destination Image, Self-Congruity, and Travel Behavior: Toward an Integrative Model. Journal of Travel Research,38(4), 340-352. doi: $10.1177 / 004728750003800402$

Spector, P. E., Cooper, C. L., \& Sparks, K. (2001). An international study of the psychometric properties of the Hofstede values survey module 1994: a comparison of individual and country/ province level results. Applied Psychology: An International review, 50(2), 269-281.

Steenkamp, J., Hofstede, F., \& Wedel, M. (1999). A Cross-National Investigation into the Individual and National Cultural Antecedents of Consumer Innovativeness. Journal of Marketing, 63(2), 55. doi: 10.2307/1251945

Tascioglu, M., Eastman, J., \& Iyer, R. (2017). The impact of the motivation for status on consumers' perceptions of retailer sustainability: the moderating impact of collectivism and materialism. Journal of Consumer Marketing, 34(4), 292-305. doi: 10.1108/jcm-03-2015-1351

Underwood, E. (1994) 'Luxury's tide turns', Brandweek, 7th March, 35, 18-22

Vigneron, F., \& Johnson, L. (2004). Measuring perceptions of brand luxury. Journal of Brand Management, 11(6), 484-506. doi: 10.1057/palgrave.bm.2540194

Wiedmann, K., \& Hennigs, N. (2013). Luxury Marketing, A Challenge for Theory and Practice (1st ed., pp. 157-169). Springer Gabler.

Wong, N., \& Ahuvia, A. (1998). Personal taste and family face: Luxury consumption in Confucian and western societies. Psychology and Marketing, 15(5), 423-441. doi: 10.1002/(sici)1520- 6793(199808)15:5<423::aid-

mar2>3.0.co;2-9

Yoo, B., Donthu, N., \& Lee, S. (2000). An examination of selected marketing mix elements and brand equity. Journal of the academy of marketing science, 28(2), 195211.

Yoo, B., \& Donthu, N. (2001). Developing A Scale to Measure the perceived quality of an internet site(SITEQUAL). Quarterly Journal of Electronic Commerce,2(1). Retrieved 8 May 2020, from https://sites.hofstra.edu/boonghee-yoo/wpcontent/uploads/sites/32/2019/08/2001_QJ EC_SITEQUAL.pdf.

Yoo, B., \& Donthu, N. (2002). Testing crosscultural invariance of the brand equity creation process. Journal of Product \& Brand Management.

Yoo, B., \& Donthu, N. (2005). The effect of personal cultural orientation on consumer ethnocentrism: Evaluations and behaviors of US consumers toward Japanese products. Journal of International Consumer Marketing, 18(1-2), 7-44.

Yoo, B., Donthu, N., \& Lenartowicz, T. (2011). Measuring Hofstede's five dimensions of cultural values at the individual level: Development and validation of CVSCALE. Journal of international consumer marketing, 23(3-4), 193-210.

Zinkhan, G. and Prenshaw, P. (1994) 'Good life images and brand name associations: Evidence from Asia, America and Europe', Advances in Consumer Research, 21 (1), 496-500 